\title{
PSİKOLOJİK İYİ HALİN SÜRDÜRÜLEBİLİR KALİTE ALGISINI YORDAMADA YÖNETİCI CİNSİYETİ DÜZENLEYİCİ ETMEN MİDIR?
}

Uzay DURAL ${ }^{2}$

Bilal ÇANKIR ${ }^{3}$

\author{
Received Date (Başvuru Tarihi): \\ $27 / 02 / 2020$ \\ Accepted Date (Kabul Tarihi): \\ $25 / 09 / 2020$ \\ Published Date (Yayın Tarihi): \\ $10 / 12 / 2020$
}

Çalıșmada ilk yazar Sorumlu Yazar (Corresponding Author) rolündedir.

$\ddot{O Z Z}$

Anahtar Kelimeler:

Sürdürülebilir Kalite Algısı,

Psikolojik İyi-Oluş,

Bilişim Sektörü,

Elektronik Sektörü

JEL Kodlarn:

C12,

I31,

M12

\section{Keywords:}

\section{Sustainable Quality}

Perception

JEL Codes:
C12
Kalitenin bir gereklilik olarak görülmesinin değişmesi ve kalitenin bir zorunluluk halini almasl, sürdürülebilir kalitenin gelişmesindeki temel etken olarak görünmektedir. Kalite algılan bu anlamda önem kazanır. Kalite algısın belirleyen etmenlerden beri özellikle yönetici kademesindeki çalışanların psikolojik iyi halleri olabilir. Bu çalışmanın amacı, sürdürülebilir kalite algısının kadın ve erkek yöneticilerin psikolojik iyi oluşlarına göre açıklayıcılığını test etmektir. Bu kapsamda bilişim ve elektronik sektörlerinde tam zamanl çalışan 388 kişinin sürdürülebilir kalite algıları ve psikolojik iyi oluşları ölçüldü. Yönetici ve çalışan gruplarından toplanan veri üzerinde çoklu gruplu yapısal eşitlik modellemesi yapıldı. Analiz sonuçlarnna göre, iş tatmini kontrol edildiğinde, psikolojik iyi oluşlarının kalite algıları üzerindeki açıklayıcılı̆̆ı kadın ve erkek yönetici gruplarına göre farklılaşmaktadır. Buna göre düşük psikolojik iyi oluş olduğunda kadın ve erkek yöneticiler benzer düzeyde düşük kalite algısına sahiptirler. Yüksek iyi oluş yaşadıklarında ise kadın yöneticilerin kalite algısı erkek yöneticilerin kalite algısına göre daha yüksek olmaktadır. Kadın yöneticiler, psikolojik iyi halleri yüksek olduğunda daha yüksek sürdürülebilir kalite atfi yapabilirler.

\footnotetext{
${ }^{1}$ Bu çalışma 23-25 Eylül 2020 tarihlerinde Erciyes Üniversitesi'nde düzenlenen 19. Uluslararası İşletmecilik Kongresi'nde sunulan bildirinin geliştirilmiş ve genişletilmiş halidir.

${ }^{2}$ Dr. Öğr. Üyesi, İstanbul Medeniyet Üniversitesi, Edebiyat Fakültesi, Psikoloji Bölümü, uzay.senoguz@medeniyet.edu.tr, https:// orcid.org/0000-0003-1578-6686

${ }^{3}$ Doç. Dr., İstanbul Medeniyet Üniversitesi, Siyasal Bilgiler Fakültesi, İşletme Bölümü, bilal.cankir@medeniyet.edu.tr,
} https://orcid.org/0000-0001-5126-8769

Business \& Management Studies: An International Journal Vol.:8 Issue:4 Year:2020, 69-82

Bu makale, araştırma ve yayın etiğine uygun hazırlanmış ve tithenticate intihal taramasından geçirilmiştir. 


\section{EXTENDED ABSTRACT}

\section{DOES MANAGER GENDER MODERATE HOW PSYCHOLOGICAL WELL- BEING PREDICTS SUSTAINABLE QUALITY PERCEPTIONS?}

\section{LITERATURE}

This study is of particular importance in terms of revealing the extent to which human resources support the sustainability efforts of the business today and in the future. This study questions how sustainable quality perception can be explained in terms of the psychological well-being of male and female managers. Organizational sustainability is defined as activities to make social growth sustainable while trying to achieve corporate growth and profitability (van Marrewijk \& Werre, 2003). Issues such as economic and social developments, protection of resources, globalization, health, and regional initiatives are useful in the development of sustainability (Çankır, Fındık \& Koçak, 2012). In this context, organizational sustainability includes agendas such as economic development, ensuring social justice, and protecting natural resources and the environment (Hahn, Pinkse, Preuss \& Figge, 2015).

Sustainable quality perception includes the extent to which employees attach importance to the sustainability activities of their businesses; and how much they include them in these activities while expressing the degree to which the organization meets the requirements of total quality management (Çankır \& Eti, 2017; Çankır \& Şahin, 2018; Arıkan \& Çankır, 2019). For example, the extent to which managers and employees collaborate to increase success in the enterprise shows the perceived quality dimension of the sustainable quality perception (Çankır \& Eti, 2017). In another example, taking into account the environmental impact in a business can reveal the perception of organizational sustainability. In the current study, the authors proposed that the perceptions of especially those at the management level regarding sustainability and quality activities may be affected by their positive and negative subjective psychological experiences and satisfaction.

\section{DESIGN AND METHOD}

\subsection{PARTICIPANTS}

Three hundred eighty-eight employees working in the information technology and electronics sectors participated in this study. An online questionnaire was sent to employees in these sectors in Istanbul in 2017 using the convenience sampling method. Data were collected from those who volunteered to participate in the study.

\subsection{DATA COLLECTION METHOD}

Employees' perception of sustainable quality was evaluated with a 13-item scale developed by Çankır and Eti (2017) in the academy sector. Psychological Well-Being Scale, which was developed by Diener et al. (2009) and consisted of eight items, was used to evaluate the well-being levels of employees. The scale was adapted to Turkish by Telef (2013). Employees' job satisfaction was measured with a fiveitem scale developed by Brayfield and Rothe (1951) and translated into Turkish by Bilgin (1995).

\subsection{QUANTITATIVE ANALYSIS}

Data analysis was performed with Mplus 7.11 (Muthen \& Muthen, 1998-2013) program. Relationships between variables were analyzed using the Pearson correlation method. For hypothesis testing, the structural equation model (SEM) analysis with multiple group regulatory variables was performed with maximum likelihood estimation. The manager and employee groups were entered into the model as multiple groups, and the gender variable was entered into the model as a regulatory variable. 


\section{FINDINGS}

The means (standard deviations) of the research variables and the relationships between variables are shown in Table 2. According to Pearson's correlation analysis, the sustainable quality perception has a significant positive correlation with psychological well-being and job satisfaction. It did not show a significant relationship with gender and position. A multi-group SEM analysis was conducted to test the research model. The fit of the research model and the data is at an acceptable level, $\chi^{2}=474.39, \mathrm{df}=207, \mathrm{TLI}=0.92, \mathrm{CFI}=0.93, \mathrm{RMSEA}=0.08$ (90\% confidence interval 0.07-0.09). Coefficients and standard errors are shown in Table 3 and Figure 1. As seen in Figure 1, the psychological well-being of both managers $(B=0.85, p<.001)$ and employees $(B=0.52, p<.001)$ predicts sustainable quality perception significantly and positively. Only in the management group, job satisfaction significantly predicts sustainable quality perception $(B=0.20, p<.01)$. The gender of the participants did not significantly predict the sustainable quality perception in both groups. In the relationship between psychological well-being and sustainable quality perception, the regulatory effect of gender is significant for the executive group $(B=-0.41, p<.05)$ and no regulatory effect was observed for the employee group. Figure 2 presents the relationship between psychological well-being and sustainable quality perception according to male and female managers.

\section{CONCLUSION}

In this study, whether sustainable quality perception can be predicted according to the psychological well-being of male and female managers was tested. Multi-group structural equation modelling was performed for managers and employee groups. When job satisfaction levels of both manager and employee group were controlled, psychological well-being predicted high-quality perception.

With the research, results were obtained by the previous studies in the literature (Çankır \& Şahin, 2018; Arıkan \& Çankır, 2019). The most important difference from these studies is that psychological well-being does not determine the sustainable quality perception of employees in every position. While there was no significant regulatory effect of gender between psychological well-being and quality perception in the employee group, this regulatory effect was found to be significant in the manager group. Being male or female managers differentiates the effect of psychological well-being on quality perceptions. Accordingly, when there is low psychological well-being, male and female managers have a similar low-quality perception. When they experience high well-being, the quality perception of female managers is higher than that of male managers. Female managers can attribute higher sustainable quality when their psychological well-being is high. 


\section{GİRIŞ}

Sürdürülebilirliğin gelişimi ile teknolojik gelişmeler işletmeleri sürekli bir şekilde değişim göstermeye doğru itmektedir (Köşker Demir, 2010). Sürekli değişimlerin yaşandığı bir ortamda, sürdürülebilirliği sağlamak oldukça zor, ama önemli olduğu için sürdürülebilir kalite kavramının üzerine çalışmalar yapılması önem kazanmaktadır. Kalitenin bir gereklilik olarak görülmesinin değişmesi ve kalitenin bir zorunluluk halini alması, sürdürülebilir kalitenin gelişmesindeki temel etken olarak görünmektedir. Kalite algılarının yordayıcıları bu anlamda önem kazanır. Kalite algısını özellikle yönetici kademesindeki çalışanların kendi psikolojik iyi oluşları ve hatta yöneticinin cinsiyeti etkileyebilir. Bu çalışma günümüzde ve gelecekte işletmelerin sürdürülebilir rekabet üstünlüğü sağlamada en önemli kaynaklarından olan insan kaynağının işletmenin sürdürülebilirlik çabalarına ne ölçüde destek verdiğini ortaya koyması açısından belirli bir önemliliğe sahiptir. Bu çalışma, sürdürülebilir kalite algısının kadın ve erkek yöneticilerin psikolojik iyi oluşları açısından ne kadar açıklanabileceğini sorgulamaktadır.

\section{KAVRAMSAL ÇERÇEVE}

\subsection{Sürdürülebilir Kalite Algısı}

Örgütlere dair kalite algısı, örgütün paydaşlarının genel olarak istek ve beklentilerinin karşılanma düzeyi çerçevesinde ele alınmaktadır (Burke, 1995; Julien \& Tsoni, 2013). Toplam kalite yönetimi anlayışında süreçlere odaklanma, iç ve dış müşteri ihtiyaçlarını tanıma, bu ihtiyaçları anlama ve geliştirme için nesnel verileri analiz etme önemli olduğu kadar iç müşteri olarak nitelendirilen çalışanın gözünden örgütün kalitesi algisına değer verilmektedir.

Örgütsel sürdürülebilirlik kurumsal büyüme ve karlılığı sağlamaya çalışırken bir yandan da toplumsal büyümeyi sürdürülebilir hale getirmeye çalışma olarak tanımlanmaktadır (van Marrewijk \& Werre, 2003). Sürdürülebilirliğin gelişiminde ekonomik ve sosyal gelişmeler, kaynakların korunması, küreselleşme, sağlık, bölgesel girişimler gibi hususların etkili olduğu ifade edilmiştir (Çankır, Fındık \& Koçak, 2012). Bu bağlamda örgütsel sürdürülebilirlik ekonomik gelişme, sosyal adaletin sağlanması 
ile doğal kaynakların ve çevrenin korunması gibi gündemleri içerir (Hahn, Pinkse, Preuss \& Figge, 2015).

Sürdürülebilir kalite algısı da çalışanların işletmelerinin sürdürülebilirlik faaliyetlerine ne kadar önem verdiklerini ve bu faaliyetlere onları ne kadar dâhil ettiklerini içerirken, örgütün toplam kalite yönetiminin gereklerini ne şekilde sağladığını algılama derecelerini ifade etmektedir (Çankır \& Eti, 2017; Çankır \& Şahin, 2018; Arıkan \& Çankır, 2019). Örneğin, işletmede başarıyı arttırmak için yönetici ile çalışanların ne kadar iş birliği içinde çalıştıkları sürdürülebilir kalite algısının algılanan kalite boyutunu göstermektedir (Çankır \& Eti, 2017). Bir başka örnekte, işletmede çevresel etki dikkate alınarak işler yapılması örgütsel sürdürülebilirlik algısını ortaya koyabilmektedir. Özellikle yönetim kademesindekilerin sürdürülebilirlik ve kalite faaliyetlerine dair algıları, onların olumlu ve/veya olumsuz öznel psikolojik deneyimleri ve memnuniyetlerinden etkilenebileceği düşünülmektedir.

\section{2. Öznel Psikolojik İyi Oluş}

Öznel psikolojik iyi oluş, bireylerin olumlu duygulanımlarını, yaşamdan genel olarak memnun olma halini tanımlar (Diener vd., 2009; Diener vd., 2010). Öznel iyi oluşu yüksek olan kişiler, süregelen bir mutluluk ve keyifli hal içindedir. Birey, geçmişini düşündüğünde, geleceğini düşündüğünde, onun için özel kişileri düşündüğünde ve şu an yaşadıklarını düşündüğünde genel olarak memnuniyet duymaktadır. Memnun olmadığı durumda da yaşamını değiştirme isteği ve hevesi vardır. Öznel iyi oluşu yüksek olan kişi, genel olarak bu deneyimleri yaşayabilir ve/veya yaşamının farklı alanlarında (örneğin, iş yerinde) deneyimleyebilir. Öznel iyi oluş düzeyi düşük olduğunda ise yaşamın çeşitli alanlarında karamsarlık gibi negatif duygulanım ve yaşamdan genel memnuniyetsizlik hali içindedirler.

$\mathrm{Bu}$ anlamda öznel psikolojik iyi oluş iş performansını belirlemede önemli bir etmen olduğu gibi (bkz., Wright \& Cropanzano, 2000), iş yerindeki sürdürülebilirlik kalite algısını da yordayabileceğini düşünmekteyiz. Kadın ve erkeklerin farklı öznel psikolojik iyi oluş deneyimledikleri de bilindiğinden (Burns \& Machin, 2010) bu 
çalışmada kadın ve erkek yöneticilerin öznel psikolojik iyi oluşlarının kalite algılarını yordayıp yordamadığı incelenecektir.

\section{3. İş Tatmini}

İş tatmini, bir çalışanın iş ve çalışmaya dair olumlu tutumudur (Locke, 1969; Loher, Noe, Moeller \& Fitzgerald, 1985). Locke'a (1969) göre iş tatminin hem bilişsel hem de duygusal öğeleri vardır. İşi değerlendirme süreci olan bilişsel öğe, işe dair olumlu hisler olan duygusal öğe ile etkileşim içindedir. İş tatminin psikolojik iyi oluş ile ilişkili olduğu, ama ayrışan iki kavram olduğu bilinmektedir (Wright \& Cropanzano, 2000). İkisinin de çıktılarından biri iş performansı ve iş kalitesidir (Judge, Parker, Colbert, Heller \& Ilies, 2001). Örneğin, yüksek kalite ve yüksek performansı destekleyen takımlarda çalışmanın iş tatmini artırabileceği belirtilmiştir (Barling, Kelloway \& Iverson, 2003). Bunun yanında işe dair tatmin değerlendirmeleri ve hisleri, örgütün ne kadar sürdürülebilir bir kaliteye sahip olduğuna dair algıları da şekillendirebilir. İş tatmini yüksek olan çalışanların kalite algısı daha yüksek olabilir. $\mathrm{Bu}$ yüzden bu çalışmada psikolojik iyi oluşa bağlı kalite algılaması incelenirken iş tatmini kontrol değişkeni olarak ele alınmaktadır.

\section{YÖNTEM}

\section{1. Örneklem}

$\mathrm{Bu}$ çalışmaya bilişim ve elektronik sektörlerde çalışan 388 kişi katılarak örneklem büyüklüğünü oluşturdu. İstanbul'da 2017 yılında bu sektörlerde çalışanlara kolayda örneklem yöntemi kullanılarak çevrimiçi anket gönderildi. Veri toplama zamanı 1 Ocak 2020'den önce olduğundan etik kurul izin belgesi gerekmemektedir. Araştırmaya gönüllü katılmayı kabul edenlerden veri toplandı. Tablo 1'de katılımcıların bilgileri sunulmaktadır.

Katılımcıların çoğunluğunu erkek çalışanlar (n = 178, \%45,9) ve erkek yöneticiler ( $n=118, \% 30,3$ ) oluşturmaktadır. Katılımcıların neredeyse üçte ikisi 32 yaş altındadır $(\mathrm{n}=252, \% 67,5)$, bekardır $(\mathrm{n}=249, \% 64,2)$ ve 4 yıldan az kıdeme sahiptir (n $=261 \% 67,2)$. Büyük çoğunluğu ise lisans ve üzeri eğitim düzeyindedir (n=309, \%79,6). 
Tablo 1. Örneklem Özellikleri $(\mathrm{n}=388)$

\begin{tabular}{|c|c|c|c|}
\hline & & $\mathrm{N}$ & $\%$ \\
\hline \multirow[t]{2}{*}{ Cinsiyet } & Erkek & 296 & 76,3 \\
\hline & Kadın & 92 & 23,7 \\
\hline \multirow[t]{2}{*}{ Pozisyon } & Yönetici & 145 & 37,4 \\
\hline & Çalışan & 243 & 62,6 \\
\hline \multirow[t]{4}{*}{ Cinsiyet*Pozisyon } & Erkek yönetici & 118 & 30,3 \\
\hline & Kadın yönetici & 27 & 7,0 \\
\hline & Erkek çalışan & 178 & 45,9 \\
\hline & Kadın çalışan & 65 & 16,8 \\
\hline \multirow[t]{4}{*}{ Kidem } & 1 yıldan az & 107 & 27,6 \\
\hline & $1-2 \mathrm{y} 1 \mathrm{l}$ & 82 & 21,0 \\
\hline & 3-4 y1l & 72 & 18,6 \\
\hline & 5 ve üzeri & 88 & 15,8 \\
\hline \multirow[t]{3}{*}{ Yaş } & $18-24$ & 136 & 35,0 \\
\hline & $25-32$ & 126 & 32,5 \\
\hline & $33-39$ & 126 & 32,5 \\
\hline \multirow[t]{2}{*}{ Medeni Durum } & Evli & 139 & 35,8 \\
\hline & Bekar & 249 & 64,2 \\
\hline \multirow[t]{2}{*}{ Eğitim Durumu } & Lise ve altı & 79 & 20,4 \\
\hline & Lisans ve üzeri & 309 & 79,6 \\
\hline
\end{tabular}

\section{2. Ölçüm Araçları}

\subsubsection{Sürdürülebilir Kalite Algısı}

Çalışanların sürdürülebilir kalite algısı, Çankır ve Eti (2017) tarafından geliştirilen akademi sektöründe geliştirilen 13 maddelik bir ölçek ile değerlendirildi. Ölçeğin örnek ifadelerinden bir tanesi şudur: "Bu işletmede işler, müşteri ihtiyacına göre düzenlenir". Her bir madde 5'li Likert tipi ölçekle (1 = Hiç katılmıyorum, 5 = Kesinlikle katılıyorum) değerlendirilir (Cronbach Alfa güvenirlik katsayısı = 0,84). Yüksek puanlar yüksek algılanan sürdürülebilir kaliteyi gösterir. 


\subsubsection{Psikolojik İyi Oluş}

Çalışanların iyi oluş düzeylerini değerlendirebilmek için Diener ve arkadaşları (2009) tarafından geliştirilen ve sekiz maddeden oluşan Psikolojik İyi Oluş Ölçeği (Psychological Well-Being Scale) kullanılmıştır. Ölçeğin Türkçeye uyarlaması Telef (2013) tarafından yapılmıştır. Ölçeğin örnek ifadelerinden bir tanesi şudur: “Geleceğim hakkında iyimserim.”. Her bir madde 7’li Likert tipi ölçekle $(1=$ Hiç katılmıyorum, 7 = Kesinlikle katılıyorum) değerlendirilir (Cronbach Alfa güvenirlik katsayısı = 0,90). Yüksek puanlar yüksek psikolojik iyi oluş algısını gösterir.

\subsection{3. İş Tatmini}

Çalışanların iş doyumları Brayfield ve Rothe'un (1951) geliştirdiği ve Bilgin'in (1995) Türkçeye çevirdiği beş maddelik ölçek ile ölçülmüştür. Örnek maddelerden biri şöyledir: “İşimi çoğu zaman severek yaparım.” Her madde 5’li Likert tipi ölçekleme (1 = "Hiç katılmıyorum.", 5 = "Kesinlikle katılıyorum.") ile değerlendirilmektedir (Cronbach Alfa güvenirlik katsayısı =0,84). Yüksek ölçek puanı yüksek düzeyde çalışanların işinden tatmin olduğunu gösterir.

\subsection{Veri Analizi}

Veri analizi Mplus 7.11 (Muthen \& Muthen, 1998-2013) programı ile yapıld1. Değişkenler arası ilişkilere Pearson korelasyon yöntemiyle bakıldı. Hipotez testi için en büyük olabilirlik kestirimi ile çoklu gruplu düzenleyici değişkenli yapısal eşitlik modeli (YEM) analizi yapıldı. Yönetici ve çalışan grupları çoklu grup olarak, cinsiyet değişkeni ise düzenleyici değişken olarak modele girildi. Modelin verilerle uyumu kikare, CFI (>.95), TLI (>.95) ve RMSEA (<.06, \%90 güven aralığı) göstergeleri ile bakıldı. CFI ve TLI için 0,95<iyi uyumu, 0,90<kabul edilebilir uyumu; RMSEA için ise 0,06> iyi uyum, 0,08> kabul edilebilir uyumu gösterir (Hu \& Bentler, 1999; Kline, 2015).

\section{BULGULAR}

Araştırma değişkenlerinin ortalamaları (standart sapmaları) ve değişkenler arası ilişkiler Tablo 2'de gösterilmektedir. Pearson korelasyon analizine göre sürdürülebilir kalite algısı, psikolojik iyi oluş ve iş tatmini ile anlamlı düzeyde pozitif korelasyona sahiptir. Cinsiyet ve pozisyon ile anlamlı ilişki göstermemiştir. 
Tablo 2. Araştırma Değişkenlerinin Ortalamaları ve Değişkenler Arası Korelasyonlar

$$
(\mathrm{n}=388)
$$

\begin{tabular}{|c|c|c|c|c|c|c|}
\hline Değişkenler & Ort. & Std. Sapma & 2 & 3 & 4 & 5 \\
\hline Sürdürülebilir Kalite Algısı & 1,86 & ,76 &, $641^{* *}$ &, $296^{* *}$ &,- 038 &,- 028 \\
\hline Psikolojik İyi Oluş & 2,11 & ,76 & - &, $357^{* *}$ & 014 &,- 068 \\
\hline İş Tatmini & 2,23 & 85 & & - &,- 080 &,$- 145^{* *}$ \\
\hline Cinsiyet $(1=$ Erkek, $0=$ Kadın $)$ & ,76 & 43 & & & - & ,092 \\
\hline Pozisyon (1 = Yönetici, $0=$ Çalışan) & 37 & 48 & & & & - \\
\hline
\end{tabular}

Araştırma modelini test etmek için çoklu gruplu YEM analizi yapıldı. Araştırma modeli ile verinin uyumu kabul edilebilir düzeydedir, $\chi^{2}=474,39, \mathrm{df}=207, \mathrm{TLI}=0,92$, $\mathrm{CFI}=0,93, \mathrm{RMSEA}=0,08$ (\%90 güven aralığ1 0,07-0,09). Katsayılar ve standart hatalar Tablo 3'de ve Şekil 1'de gösterilmektedir.

Tablo 3. Yönetici ve Çalışan Grupları İçin YEM Analizi Bulguları

\begin{tabular}{|c|c|c|c|c|c|c|}
\hline Sonuç Değişkeni: & & & & & & \\
\hline Sürdürülebilir Kalite Alg1sı & Yönetici Grub & $(n=145)$ & & Çalışan Grubı & $(\mathrm{n}=24$ & \\
\hline & Std. olmayan & Std. & Std. & Std. olmayan & Std. & Std. \\
\hline & katsayı & hata & katsayı & katsayı & hata & katsayı \\
\hline Psikolojik İyi Oluş & 0,844 & 0,114 & $0,854^{* * *}$ & 0,491 & 0,107 & $0,516^{* * *}$ \\
\hline Cinsiyet $(1=$ Erkek,$\quad 0=$ & 0,518 & 0,288 & 0,261 & $-0,240$ & 0,256 & $-0,152$ \\
\hline Kadın) & & & & & & \\
\hline Cinsiyet $x$ Psikolojik İyi Oluş & $-0,310$ & 0,126 & $-0,409^{*}$ & 0,100 & 0,116 & 0,165 \\
\hline İş Tatmini & 0,197 & 0,064 & $0,201^{* *}$ & 0,033 & 0,045 & 0,041 \\
\hline
\end{tabular}


Şekil 1'de görüldüğü gibi sürdürülebilir kalite algısını, hem yöneticilerin $(B=$ $0,85, \mathrm{p}<.001)$ hem de çalışanların $(B=0,52, \mathrm{p}<.001)$ psikolojik iyi oluşları anlamlı ve pozitif yönde yordamaktadır. Sadece yönetici grubunda iş tatmini sürdürülebilir kalite algısını anlamlı düzeyde yordamaktadır $(B=0,20, \mathrm{p}<.01)$.

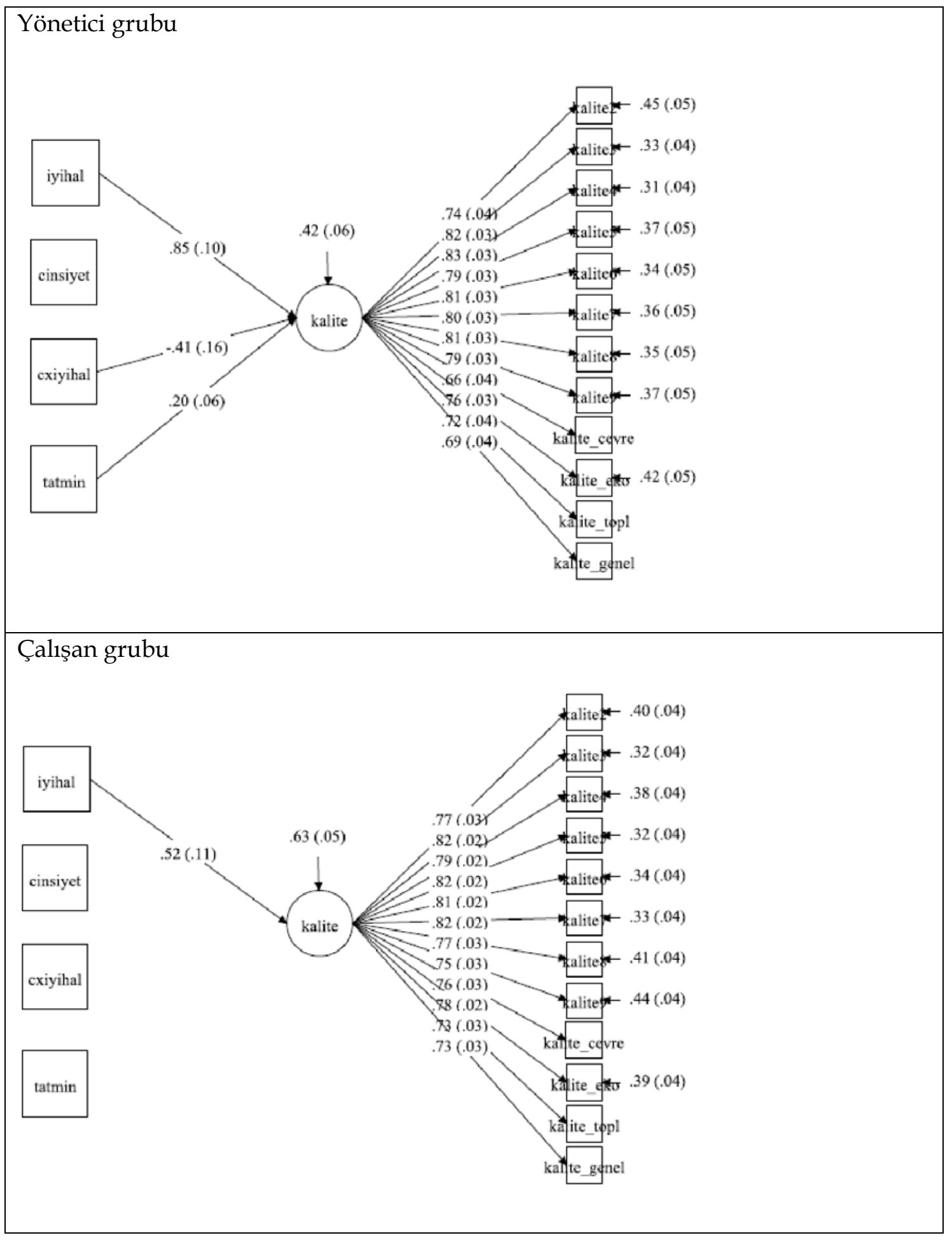

Şekil 1. Yönetici ve Çalışan Gruplarına Göre YEM Analizinde Anlamlı Çıkan Yollar 
Sürdürülebilir kalite algısını katılımcıların cinsiyeti iki grupta da anlamlı düzeyde yordamamaktadır. Psikolojik iyi oluş ile sürdürülebilir kalite algısı arasındaki ilişkide cinsiyetin düzenleyici etkisi ise yönetici grubu için anlamlı düzeydedir $(B=-0,41, \mathrm{p}<.05)$ ve çalışan grubu için düzenleyici etki görülmemiştir. Şekil 2'de kadın ve erkek yöneticilere göre psikolojik iyi oluş ve sürdürülebilir kalite algısı ilişkisi sunulmaktadır.

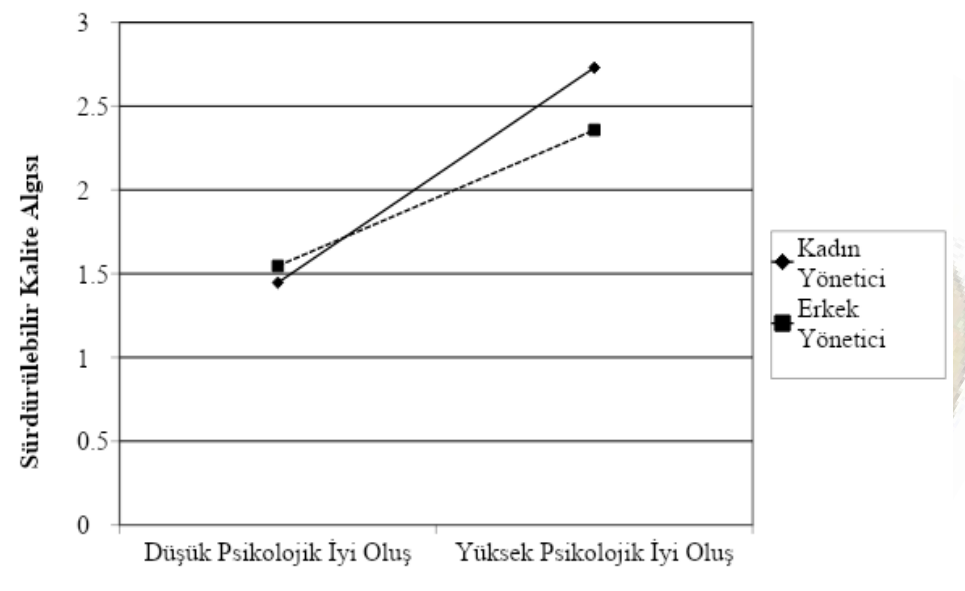

Şekil 2. Yönetici Grubunda Cinsiyet Değişkeninin Sürdürülebilir Kalite Algısı ile Psikolojik İyi Oluş Arasındaki İlişkiyi Düzenlemesi

Buna göre hem kadın yöneticilerin hem de erkek yöneticilerin psikolojik iyi oluş düzeyleri düşük olduğunda sürdürülebilir kalite algısı düşüktür. Tam aksine kadın yöneticilerin psikolojik iyi oluşları yüksek olduğunda ise sürdürülebilir kalite algıları erkek yöneticilere göre daha yüksektir.

\section{SONUÇ}

Bu çalışmada, sürdürülebilir kalite algısının kadın ve erkek yöneticilerin psikolojik iyi oluşlarına göre yordanıpyordanamayacağı test edilmiştir. Yönetici ve çalışan gruplarına yapılan çoklu gruplu yapısal eşitlik modellemesi yapıldı. Hem yönetici hem de çalışan grubunun iş tatmin düzeyleri kontrol edildiğinde psikolojik iyi oluşları yüksek kalite algısını yordadı.

Araştırma ile literatürde bundan önce yapılan çalışmalarla da (Çankır \& Şahin, 2018; Arıkan \& Çankır, 2019) uyum gösteren sonuçlara ulaşılmıştır. Bu çalışmalardan 
en önemli farkı psikolojik iyi halin her pozisyondaki çalışanın sürdürülebilir kalite algısını belirlemediğidir. Çalışan grubunda psikolojik iyi hal ile kalite algısı arasında cinsiyetin anlamlı düzeyde düzenleyici etkisi görülmez iken yönetici grubunda bu düzenleyici etki anlamlı düzeyde bulundu. Yöneticilerin kadın veya erkek olması psikolojik iyi oluşlarının kalite algıları üzerindeki etkisini farklılaştırmaktadır. Buna göre düşük psikolojik iyi oluş olduğunda kadın ve erkek yöneticiler benzer düzeyde düşük kalite algısına sahiptirler. Yüksek iyi oluş yaşadıklarında ise kadın yöneticilerin kalite algısı erkek yöneticilerin kalite algısına göre daha yüksek olmaktadır. Kadın yöneticiler, psikolojik iyi halleri yüksek olduğunda daha yüksek sürdürülebilir kalite atf1 yapabilirler. 


\section{KAYNAKÇA}

Arıkan, S., \& Çankır, B. (2019). Gıda ve Finans Sektöründe Çalışan Performansı Hangi Faktörlerden Etkileniyor? Sürdürülebilir Kalite Algısı, Psikolojik İyi Oluş ve Çalışmaya Tutkunluk Değişkenlerinin Rolü. OPUS Uluslararası Toplum Araştırmaları Dergisi, 12, 1-1.

Barling, J., Kelloway, E. K., \& Iverson, R. D. (2003). High-quality work, job satisfaction, and occupational injuries. Journal of Applied Psychology, 88(2), 276.

Brayfield, A. H., \& Rothe, H. F. (1951). An index of jobsatisfaction. Journal of AppliedPsychology, 35(5), 307-311.https://doi.org/10.1037/h0055617

Burke, R. J. (1995). Management practices, employees' satisfaction and perceptions of quality of service. Psychological Reports, 77(3), 748-750.

Burns, R. A., \& Machin, M. A. (2010). Identifying gender differences in the independent effects of personality and psychological well-being on two broad affect components of subjective well-being. Personality and Individual Differences, 48(1), 22-27.

Çankır, B. \& Eti, S. (2017). Üniversitelerde Sürdürülebilirlik ve Kalite: Sürdürülebilir Kalite Algısı Ölçeği (SKA-Ö)'nin Geliştirilmesi, Geçerlik ve Güvenirlik Çalışması. II. Uluslararası Yükseköğretim Çalışmaları Konferansı. 12-14 Ekim. Antalya.

Çankır, B., \& Şahin, S. (2018). Sürdürülebilir kalite algısının işten ayrılma niyeti üzerindeki etkisinde iş tatmininin aracı rolü. Uluslararası İktisadi ve İdari İncelemeler Dergisi, 17, 135-146.

Çankır, B., Fındık, H. \& Koçak, Ö.E. (2012). Sürdürülebilirlik ve sürdürülebilir organizasyon yönetimi. 1st International Conference on Sustainable Business andTransitionsforSustainable Development, 11-13 Ekim, 375-385.

Diener, E., Wirtz, D., Biswas-Diener, R., Tov, W., Kim-Prieto, C., Choi, D. W., \& Oishi, S. (2009). New measures of well-being. In Assessing well-being (pp. 247-266). Springer, Dordrecht.

Diener, E., Wirtz, D., Tov, W., Kim-Prieto, C., Choi, D. W., Oishi, S., \& Biswas-Diener, R. (2010). New well-being measures: Short scales to assess flourishing and positive and negative feelings. Social indicators research, 97(2), 143-156.

Hahn, T., Pinkse, J., Preuss, L., \& Figge, F. (2015). Tensions in corporate sustainability: Towards an integrative framework. Journal of Business Ethics, 127(2), 297-316.

Hu, L. T., \& Bentler, P. M. (1999). Cut off criteria for fit indexes in covariance structure analysis: Conventional criteria versus new alternatives. Structural equation modeling: a multidisciplinary journal, 6(1), 1-55. 
Judge, T. A., Parker, S. K., Colbert, A. E., Heller, D., \& Ilies, R. (2002). A cross-cultural review. In N. Anderson \& D. S. Ones (Eds.), Handbook of industrial, work and organizational psychology, Vol. 2 (pp. 25-52). Thousand Oaks, CA: Sage.

Julien, A., \& Tsoni, C. (2013). Front-line employee versus customer perceptions of quality attributes. Quality Management Journal, 20(2), 48-59.

Kline, R. B. (2015). Principles and practice of structural equation modeling. Guilford publications.

Köşker Demir, E. (2010). Rekreasyonel Spor Hizmeti Veren İşletmelerde Kalite Ölçeği: Geçerlik Güvenirlik Çalışması. Yüksek Lisans Tezi, Gazi Üniversitesi Sağlık Bilimleri Enstitüsü, Ankara.

Locke, E. A. (1969). What is jobsatisfaction?.Organizationalbehaviorandhumanperformance, 4(4), 309-336.

Loher, B. T., Noe, R. A., Moeller, N. L., \& Fitzgerald, M. P. (1985). A meta-analysis of the relation of job characteristics to job satisfaction. Journal of applied psychology, 70(2), 280.

Muthén, L. K., \& Muthén, B. O. (1998-2013). Mplus (version 7.11) [Computer software]. Los Angeles, CA: Muthén \& Muthén.

van Marrewijk, M., \& Werre, M. (2003). Multiple levels of corporate sustainability. Journal of Business Ethics, 44, 107-119.

Wright, T. A., \& Cropanzano, R. (2000). Psychological well-being and job satisfaction as predictors of job performance. Journal of occupational health psychology, 5(1), 84 . 